\title{
Selection and Application of the Authentic Materials in Spoken-Chinese Teaching
}

\author{
Zhongli Guo ${ }^{1}$ and Yuanhong $\mathrm{Li}^{1}$ \\ YYunnan Normal University, China \\ 1211277803@qq.com, 1287404841@qq.com
}

Keywords: Authentic Materials; Spoken-Chinese Speaking Class; Selection and Application

\begin{abstract}
The objective of this paper is to empirically study the selection and application of the Authentic Materials in spoken-Chinese teaching, putting forward the teaching strategies and problems that should be paid attention to. This paper takes input hypothesis and output hypothesis as the theoretical basis, Communicative Approach and Task-based Approach as the basic teaching methods, using teaching experiment, classroom observation and other research methods to collect data from 12 foreign students in the intermediate spoken-Chinese class, and then testify the practicability of the authentic materials. The empirical results suggest that used the authentic materials as an auxiliary material has a significant and positive influence on the spoken-Chinese teaching. Almost all the students accept and are found of learning authentic materials. Experts and peers also agree that teachers should use this kind of teaching material. However, there some problems have been found during the study, such as unsuccessful input performance, inappropriate corpus, inappropriate processing methods of corpus.
\end{abstract}

\section{Introduction}

The Authentic Materials refer to language materials designed for native speakers in the target language country, not for language teaching purposes ${ }^{[1]}$. The importance of applying the Authentic Materials to the teaching of Chinese as a foreign language has been counter-copied in the previous studies with quite rich researches of its application. However, the introduction of the Authentic Materials into the Chinese classroom is still a minority, and the existing research results cannot meet the actual needs of classroom teaching. Therefore, how to let language learners dock Chinese learning resources? How to use the Authentic Materials in teaching Chinese speaking? Should we process the Authentic Materials? How is the Authentic Materials in the Chinese speaking class? All these issues are topics worth exploring.

According to the requirements of the six levels of HSK, the Chinese learners in the text refer to learners who have passed the HSK Level 3 or 4 exam and master 600-1200 common vocabulary or have equivalent language skills. They need to complete basic communication tasks in Chinese and talk about topics in related fields ${ }^{[2]}$. For students, the use of the Authentic Materials for teaching in the Chinese speaking class can make students have something to say in the real situation, which is conducive to mobilizing students' learning enthusiasm and improving learners' interest in learning and segment output. In this paper, 12 foreign students from 10 countries will participate in the practice of the selection and application of the Authentic Materials.

\section{Application Experiment of the Authentic Materials in Spoken-Chinese Teaching}

The specific research path of the study is divided into pre-teaching experiments, during teaching experiments, and after teaching experiments.

Pre-teaching Experiments. The selection of the Authentic Materials before the teaching experiment mainly refers to the basic principles proposed by Tomlinson ${ }^{[3]}$. Therefore, it is necessary to fully consider the learner's learning needs, the existing level of cognition, the level of language, and the environment in which teachers teach languages. It is also necessary to fully consider the appropriateness of the Authentic Materials itself to see if it meets the teaching objectives of intermediate speaking and whether it can arouse learners' interest in learning and so 
on.

The Authentic Materials include print materials and auditory materials, which are divided into three categories according to their functions: the first is the corpus used for the teaching of new words, the corpus is simple with contain. The second is the corpus used for functional sentence-style lectures, that is, notices, indication signs, network information, maps and other corpora. The third is the corpus used for oral activities, the corpus is closely related to daily life through network resources and contains Chinese culture and social hotspots.

Implement Teaching Experiments. Teachers rely on the textbook "Developing Chinese - Intermediate Speaking". (I), Integrating the Authentic Materials into the teaching content of the topic, structure, function and culture point, and mainly use "Task-based Approach", with the methods of "heuristic teaching" and "scenario teaching" to enable students to participate in classroom learning, engage in real communication to the maximum extent, and to achieve the teaching objectives on the premise of ensuring teaching efficiency.

In the teaching process, carry out classroom observation and recording, including self-monitoring of teachers' authentic corpus input quality, and peer experts' evaluation of classroom teaching quality. And use the mobile phone, voice recorder, and other tools to record the spoken output of the students' speaking activities for further analysis after class.

The self-monitoring of teachers' authentic corpus input quality is based on the two basic principles of "language input method" proposed by Jin Honggang ${ }^{[4]}$. The monitoring content includes the total amount of language input associated with the selected the Authentic Materials, the effective input, and the teaching methods used in the use of the authentic corpus.

The object evaluation of the quality of classroom teaching by peer experts is the "segmented standard of Chinese teaching evaluation" mentioned in the author's reference to Yang Yi's "Chinese Teaching Evaluation" [5]. The "four-level scale" is the evaluation method of excellent, good, medium and poor, and the indicators are quantified according to the teaching steps, and then the "classroom teaching quality evaluation form" is produced.

After the Teaching Experiment. All-around research and analysis after teaching experiments are the most important. First of all, teachers use questionnaires and after-school interviews to understand the degree of acceptance and likeness of students and experts in the Authentic Materials and provide opinions and suggestions for classroom teaching. Secondly, analyzing the records of classroom observation, evaluating the quality of students' oral output, conducting self-assessment on teaching quality, finding problems, and proposing specific teaching strategies.

This experiment refers to the effective output proposed by Jin Honggang (2017) for the monitoring method of the quality and quantity of oral output. In the oral activity, the learner's oral output is observed and recorded. From the four aspects of output, fluency, complexity, and accuracy, the corresponding score is given corresponding to the four-level scale and then analyzed.

\section{Teaching Experiment's Effect and Evaluation}

Teachers' Feedback of Teaching Effect. The teacher's self-monitoring on the input of the Authentic Materials mainly examines whether it provides rich language input, whether it provides detailed expansive input and the real situation of the Authentic Materials input. The results show that teachers input a variety of real corpora in the teaching process, using a variety of methods for teaching, under the premise of mainly training students' conversational communication skills, they also train students' listening skills and reading skills. In general, the input from the teachers of the Authentic Materials are sufficient, and the pre-school plan is basically realized. While explaining and practicing the authentic materials, the rich input and detailed expansive input are carried out, which means the application of the Authentic Materials is effective. However, it has also been found that the unsuccessful input performance is as follows: the students are still ignorant after the teacher's explanation; the interaction between the students and the teachers is not satisfactory; Teachers are not professional enough when teaching, and they may provide wrong professional knowledge.

After the teachers' self-monitoring of the Authentic Materials input, teacher do the students' 
Questionnaire. There are 7 questions in the questionnaire after the course, which reflect the students acceptance of the Authentic Materials, the degree of likeness and the views on the Authentic Materials: $66.7 \%$ of the students expressed their preference for this lesson, and they believed that the corpus can be understood. The Authentic Materials is helpful for their Chinese learning. 66.7\% of students have a normal degree of acceptance of the video materials; $75 \%$ of students have a high degree of acceptance of graphic materials. In contrast, students prefer graphic corpus. From the students' expectations of the Authentic Materials, $41.67 \%$ of the students hope to use the Authentic Materials for language learning in the teaching process, and $41.67 \%$ of the students still handed the right to make decisions to the teacher.

At last, 3 experts and 2 peers were invited to attend classes and evaluate the teaching quality. The average score of 5 teachers was divided into standard scores. The overall score of the evaluation scale is good. The overall performance of the teacher in this teaching is good, the teaching purpose is good, the teaching effect is obvious, and the experimental results are valid and reliable. Based on this result, the next step in the study of the Authentic Materials can be carried out. For the selection and use of the Authentic Materials in the assessment scale, the standard score is the average score of the scores of the five assessment scales. The results are shown in Table 1:

Table 1 Rating Results for The Authentic Materials Selection and Application

\begin{tabular}{|c|c|c|c|}
\hline \multicolumn{2}{|c|}{ Selection of the Authentic Materials } & $\begin{array}{l}\text { Average } \\
\text { score }\end{array}$ & Grade \\
\hline Index 1 & $\begin{array}{l}\text { Is the teacher's explanation method } \\
\text { appropriate and whether the corpus selection is } \\
\text { appropriate? }\end{array}$ & 3 & Good \\
\hline Index 2 & $\begin{array}{l}\text { Are the corpus selection of new words and } \\
\text { functional sentences appropriate? }\end{array}$ & 2.6 & Good \\
\hline Index 3 & $\begin{array}{l}\text { Whether the corpus of topic discussion and } \\
\text { cultural introduction is appropriate }\end{array}$ & 2.8 & Good \\
\hline Index 4 & $\begin{array}{l}\text { Whether the selected corpus is suitable for the } \\
\text { course type }\end{array}$ & 3.4 & $\begin{array}{l}\text { Excell } \\
\text { ent }\end{array}$ \\
\hline \multicolumn{4}{|c|}{ Use of the Authentic Materials } \\
\hline Index 5 & $\begin{array}{l}\text { Whether the teacher is clear and accurate when } \\
\text { explaining the Authentic Materials? }\end{array}$ & 2.4 & Intermediate \\
\hline Index 6 & $\begin{array}{l}\text { Whether the processing of the corpus and the } \\
\text { method of use are effective? }\end{array}$ & 2.8 & Good \\
\hline Index 7 & Is the teacher's input to the corpus sufficient? & 2.8 & Good \\
\hline Index 8 & $\begin{array}{l}\text { Is the distribution of corpus in the Authentic } \\
\text { Materials and textbook reasonable? }\end{array}$ & 3 & Good \\
\hline Index 9 & $\begin{array}{l}\text { Are students enthusiastic about participating in } \\
\text { the learning and tasks of the Authentic Materials? }\end{array}$ & 3 & Good \\
\hline
\end{tabular}

From the feedback of experts and peers, first of all, the corpus selection for different teaching links has not reached 3 points, but the overall corpus suitability is excellent, which in line with the speaking class; Secondly, teachers' processing and methods of using corpus have been recognized by experts and peers. The input of the Authentic Materials has also been well evaluated, and students have maintained a high level of participation; Finally, the teacher explained whether the clarity is 2.4 or not.

Students' Learning Effect Feedback. Teachers' Monitoring of Students' Output in Speaking Activities require students to organize a 3-minute speech entitled "My Hometown or Country" within the specified time. In the country, one person from each group took the stage to give a speech. A total of 6 students will give a speech on behalf of the group. Through classroom observation and recording, the author obtained a record of the output of these students and the quality of spoken output. The results show that only 2 of the 6 students have an output of fewer than 2 minutes. Although the output is different, the average level of 2.63 is in a good grade, while the 
average output quality at 3.13, which is in good condition. Combined with the teacher observation and statistical results, it is known that the overall output of the students has an effect, and the prescribed language communication tasks are completed, and the expected goals are basically achieved.

Table 2 Rating Results about the Students' Learning Process

\begin{tabular}{|c|c|c|c|}
\hline \multirow[b]{2}{*}{ Index } & & \multicolumn{2}{|r|}{ Unit: [Point] } \\
\hline & & $\begin{array}{l}\text { Average } \\
\text { score }\end{array}$ & Grade \\
\hline Index 1 & $\begin{array}{l}\text { Are students enthusiastic about participating in the } \\
\text { learning and tasks of the Authentic Materials? }\end{array}$ & 3.0 & Good \\
\hline Index 2 & $\begin{array}{l}\text { Are students actively involved in multiple classroom } \\
\text { activities? }\end{array}$ & 2.8 & Good \\
\hline Index 3 & $\begin{array}{l}\text { Can students fluently give their own reasonable } \\
\text { opinions on the topics and tasks are given? }\end{array}$ & 2.6 & Good \\
\hline Index 4 & $\begin{array}{l}\text { Whether the students' response is accurate, that is, } \\
\text { whether the language rules are mastered? }\end{array}$ & 2.4 & Intermediate \\
\hline Index 5 & $\begin{array}{l}\text { Can students take the initiative to ask questions or } \\
\text { propose insights? }\end{array}$ & 2.2 & Intermediate \\
\hline
\end{tabular}

Three experts and two peers scored the learning process of this lesson in the "Speaking Classroom Teaching Assessment Scale". The results show that the students' attitudes are correct, and they are more actively involved in the relevant learning and tasks of the Authentic Materials; Students can give their own reasonable opinions on the topic and have a positive impact. The students are not very accurate in the mastery of the language rules, only the state of compliance; although improved, the learning initiative is poor. This not only affects the learning effect but also is not conducive to the use of the Authentic Materials.

\section{Evaluation of Teaching Experiments}

In the teaching, two texts and six classes of teaching were designed. After discussion and analysis, we found the advantages and problems of the Authentic Materials in the teaching of spoken-Chinese.

The advantages of the Authentic Materials in the selection and classroom teaching applications. First, the selected the Authentic Materials includes paper materials and audio-visual materials, which are derived from the Internet, newspapers, and even roadside signs. Its diversity helps students understand Chinese culture while learning Chinese through a rich channel.

Then, the Authentic Materials is conducive to the creation of a harmonious atmosphere in the classroom and the presentation of good results. The Authentic Materials not only allows students to actively participate in classroom learning but also promotes the learning initiative. For example, when learning geography and climate expressions, teachers display a map of China, and students will actively find the area they know on the map, or ask, or inform the teacher of their location.

Issues with the Selection of True Corpus. It is less relevant to the text. In the discussion of topics, it is better to focus on the discussion of the textbook corpus to cater to the characteristics of the times and the hotspots of the society. If the video speed is too fast or the sound is not good, the students can't keep up with the speed, which causes the teacher to waste teaching time and delay the teaching progress to make the students understand the video content. Finally, some unprocessed the Authentic Materials is not necessarily suitable for teaching. For example, in the discussion of the topic of "guest words", the mixed corpus of Chinese and English was used. The students' attention was diverted by the familiar English, and the target language environment in the Chinese classroom was destroyed.

Issues with the Use of The Authentic Materials. Firstly, ignoring time for inputting rich corpus, resulting in serious overtime for explanations and drills, can only reduce the preparation time of activities, which slows down the teaching progress and reduces the chances of students' 
concentrated output. Secondly, the authentic corpus of the cultural import link and the warm-up link is insufficient but the use of the Authentic Materials in other links is excessive. Although the students did oral activities and output of spoken language, they did not make the most of their time to participate in the classroom. Finally, the weak professional quality of teachers leads to the lack of clarity in explaining the words added in the Authentic Materials, and the loss of the supplementary meaning of vocabulary and corpus.

\section{Teaching Strategies for the Selection and Application of The Authentic Materials Based on Teaching Practice}

The choice and selection of the Authentic Materials should be closely related to teaching objectives. The teaching goal is the starting point and destination of teaching, and it is also the key to measuring the success of the course. The Authentic Materials chosen should achieve the goal of oral teaching at the intermediate level, satisfy the daily communication of the students, and be able to express it systematically to a certain extent. Therefore, speeches, micro-documentaries, conversations, etc. can be selected. Then, according to the specific teaching objectives of different texts, design a variety of classroom activities, such as topic discussion, group debate, news interviews and so on.

The selection of the Authentic Materials should conform to the norms, common and typical of the national lingua franca. The corpus used for spoken-Chinese class, whether it is textbooks or auxiliary resources, should be strictly screened in accordance with the national language, that is, the standard of Mandarin, especially audiovisual clips. The corpus with regional color and historical color has no effect on daily communication and is not suitable for language teaching. Therefore, we must choose the Authentic Materials that is dominated by Mandarin. Therefore, the common corpus of life should be chosen in a biased manner, and the typical corpus that meets the student's language level and the content of the course. In order to ensure that students can understand the input, some real corpora should be processed according to requirements after selection to meet the teaching needs.

Import and input of the Authentic Materials should help assist teaching. Teachers should integrate the content of the text with authentic materials, carefully conceive, plan and lay out the course. Teachers can introduce the Authentic Materials in a timely manner in the teaching process of organizing teaching, reviewing, teaching new content, consolidating new content and arranging extracurricular assignments. It is possible to arouse students' interest by a small topic which is real, to stimulate thinking, and to let students put forward their opinions and warm up. The Authentic Materials can also be applied to the topic discussion process, with audiovisual clips as the mainstay. Students can directly acquire knowledge and learn relevant communicative terms by watching videos. Finally, it is used in oral activities, from easy to difficult, interlocking. In the use, teachers should consider the time, rhythm and intensity of the authentic corpus, strictly control according to the progress of the classroom, and highlight the key points. Finally, according to the authentic corpus given by the teachers, students can learn culture and language in depth after class to improve their social communication skills, stimulate their interest and thinking of Chinese culture and social phenomena. Besides this, textbook plays a very important role in the four major aspects of teaching activities. Therefore, the Authentic Materials cannot take over the dominating place and should be used as an auxiliary material to teach in a targeted and efficient manner.

\section{References}

[1] M.Q. Zhu.: World Chinese Teaching Association Newsletter, Vol. 11 (2011) No.3, p.29. (In Chinese)

[2] Information on http://www.hanban.cdu.cn/tests/index.html. (In Chinese)

[3] Tomlinson B: Materials development in language teaching (Cambridge University Publication, 1998), p.7.

[4] H.G. Jin: World Chinese Teaching, Vol. 25 (2011) No.1, p.78, 2011, 25 (01): 78-98. (In 


\section{Chinese)}

[5] Y. Yang: Evaluation of Chinese Teaching (Beijing Language and Culture University Publication, China, 2008), p.165. (In Chinese)

[6] L. Wang: The Application of Paper Advertising the Authentic Materials in Task-Based Speaking Activities in Teaching Chinese as a Foreign Language (MS., East China Normal University, China, 2010), p.8. (In Chinese)

[7] J.L. Gao. Research on the Application of Film and TV Works in Teaching Chinese as a Foreign Language (MS., Lanzhou University, China, 2014). (In Chinese)

[9] Q.Z. Zhang and N. Yu: Teaching and Research in Teaching Chinese as a Foreign Language, Vol.00 (2013), p.12. (In Chinese)

[10] K. Yang. Modern Language (Academic Synthesis), Vol.08 (2014), p.99 (In Chinese)

[11] Wong V, Kwok P and Choi N: EltJournal, (1995) 